\title{
Identification of Mycobacterium tuberculosis complex based on amplification and sequencing of the oxyR pseudogene from stored Ziehl-Neelsen-stained sputum smears in Brazil
}

\author{
Marcio Roberto Silva ${ }^{1,2} /+$, Mark Drew Crosland Guimarães², \\ Vania Maria de Oliveira', Aline dos Santos Moreira ${ }^{3}$, Ronaldo Rodrigues da Costa ${ }^{4,5}$, \\ Kelly Cristina Ferreira Abi-Zaid ${ }^{5}$, Adalgiza da Silva Rocha ${ }^{6}$, Philip Noel Suffys ${ }^{6}$
}

\begin{abstract}
EMBRAPA Gado de Leite, Ministério da Agricultura, Pecuária e Abastecimento, Juiz de Fora, MG, Brasil Programa de Pós-Graduação em Saúde Pública, Departamento de Medicina Preventiva e Social, Faculdade de Medicina, Universidade Federal de Minas Gerais, Belo Horizonte, MG, Brasil ${ }^{3}$ Laboratório de Genômica Funcional e Bioinformática ${ }^{6}$ Laboratório de Biologia Molecular Aplicada a Micobactérias, Instituto Oswaldo Cruz-Fiocruz, Rio de Janeiro, RJ, Brasil ${ }^{4}$ Hospital Universitário, Universidade Federal de Juiz de Fora, Juiz de Fora, MG, Brasil ${ }^{5}$ Hospital João Penido, Fundação Hospitalar do Estado de Minas Gerais, Juiz de Fora, MG, Brasil
\end{abstract}

A cross-sectional analysis of stored Ziehl-Neelsen (ZN)-stained sputum smear slides (SSS) obtained from two public tuberculosis referral laboratories located in Juiz de Fora, Minas Gerais, was carried out to distinguish Mycobacterium bovis from other members of the Mycobacterium tuberculosis complex (MTC). A two-step approach was used to distinguish $\mathrm{M}$. bovis from other members of MTC: (i) oxyR pseudogene amplification to detect MTC and, subsequently, (ii) allele-specific sequencing based on the polymorphism at position 285 of this gene. The oxyR pseudogene was successfully amplified in 100 of 177 (56.5\%) SSS available from 99 individuals. No molecular profile of $\mathrm{M}$. bovis was found. Multivariate analysis indicated that acid-fast bacilli (AFB) results and the source laboratory were associated $(p<0.05)$ with oxyR pseudogene amplification. SSS that were AFB++ SSS showed more oxyR pseudogene amplification than those with AFB0, possibly due to the amount of DNA. One of the two source laboratories presented a greater chance of oxyR pseudogene amplification, suggesting that differences in sputum conservation between laboratories could have influenced the preservation of DNA. This study provides evidence that stored ZN-SSS can be used for the molecular detection of MTC.

Key words: oxyR pseudogene - polymerase chain reaction - sputum smear - Mycobacterium tuberculosis Mycobacterium bovis - molecular sequence data

Sputum smear microscopy is the most cost-effective method of screening for pulmonary tuberculosis (TB) and is used in most developing countries where culturing is usually impossible (Collins \& Grange 1983, Daborn \& Grange 1993, Cosivi et al. 1995, 1998, Roxo 1997, Wedlock et al. 2002). When primary isolation of mycobacteria is performed, Löwenstein-Jensen medium containing glycerol is the most widely available and is used for tuberculosis culture that generally does not support growth of field strains of Mycobacterium bovis.

Although most cases of human TB are caused by $M y$ cobacterium tuberculosis, concerns over M. bovis have been expressed and are based on several observations. Firstly, occurrence of outbreaks of multidrug-resistant (MDR) M. bovis strains among hospitalized human immunodeficiency virus (HIV)-infected patients have been

Financial support: CNPq (410595/2006-3)

+ Corresponding author:mrsilva@cnpgl.embrapa.br

Received 25 April 2010

Accepted 12 November 2010 observed (Blázquez et al. 1997, Samper et al. 1997, Rivero et al. 2001). This fact highlights the high spread risk of MDR M. bovis, especially in parts of Africa where $M$. bovis animal diseases and HIV human infection co-exist. Secondly, transmission from patients with pulmonary $M$. bovis disease to immune-competent contacts also appears to occur (Long et al. 1999, Evans et al. 2007). Thirdly, the reemergence of human $M$. bovis carried by immigrants from regions where bovine tuberculosis is still prevalent have been documented in Europe and also on the United States-Mexico border (Wilkins et al. 1986, Dankner et al. 1993, Dankner \& Davis 2000, LoBue et al. 2003). Finally, some 7,000 new cases of TB due to $M$. bovis may arise each year in Latin America (PAHO 1991).

Identification of mycobacteria by conventional biochemical identification methods is laborious and timeconsuming and is not often performed by diagnostic laboratories. Therefore, other methods to differentiate M. bovis from other members of M. tuberculosis complex (MTC) that are faster and at least as equally or more sensitive than the classical methods are urgently needed. Such methods would aid in the identification and treatment of patients due to the intrinsic resistance of M. bovis to pyrazinamide (Konno et al. 1967) and for purposes of conducting epidemiological investigations (Espinosa de los Monteros et al. 1998). 
In Escherichia coli and Salmonella typhimurium, the $\operatorname{oxy} R$ gene functions as a sensor and transcriptional regulator of proteins involved in the oxidative stress response (Farr \& Kogoma 1991). This protective response of $o x y R$ was evident in the saprophytic Mycobacterium smegmati but absent in the MTC and the Mycobacterium avium complex (MAC). However, homologues of the oxyR gene have been isolated from MTC and MAC (Sherman et al. 1995). While the MAC $\operatorname{oxy} R$ appears intact, the oxyR homologue of MTC contains numerous deletions and frameshifts and probably does not encode a functional protein; it is referred to as a pseudogene (Sherman et al. 1995). Inasmuch as pseudogenes accumulate mutations at an increased rate compared with functional genes, Sreevatsan et al. (1996, 1997) described a polymorphic nucleotide located at position 285 of the $\operatorname{oxy} R$ pseudogene that differentiates $M$. bovis from other complex members. All M. bovis strains had an adenine residue at nucleotide 285 while all M. tuberculosis strains had guanine in the same position.

Espinosa de los Monteros et al. (1998) described the use of an allele-specific polymerase chain reaction (PCR) method for detecting polymorphisms in $\operatorname{oxy} R$ to quickly and easily differentiate $M$. bovis from MTC. They found that the system based on oxyR could differentiate all of the M. bovis strains tested (including those isolated from goats).

Genetic analyses for the identification of mycobacteria species have been more common from isolates (Espinosa de los Monteros et al. 1998), but were rarely used in primary biological specimens or stored materials [sputum smear slides (SSS) or paraffin blocks]. The systems based on amplification and sequencing of the oxy $R$ pseudogene from stored Ziehl-Neelsen (ZN)-stained SSS for identifying strains and distinguishing $M$. bovis from other members of the MTC have been implemented by research laboratories in Brazil (Da Silva Rocha 2009). Public health programs and epidemiological studies may benefit from such methods. This paper presents exploratory data describing the characterization of mycobacteria by molecular methods using DNA extraction, amplification and sequencing of the $\operatorname{oxy} R$ pseudogene using stored ZN-stained SSS obtained from patients with TB diagnosed at two public referral laboratories from Juiz de Fora, state of Minas Gerais (MG).

The choice of MG for the present study was due to the fact that a tuberculin survey (1999) was performed on 1,600 herds and 23,000 cattle, including Juiz de Fora. The estimated prevalence of tuberculin reactors was $0.85 \%$. Meanwhile, M. bovis infection in cattle affects $5 \%$ of all herds and $15 \%$ of herds that presented greater ability to produce milk (MAPA 2006). Although no zoonotic TB cases due to M. bovis have been reported by Municipal Health Department of Juiz de Fora, the authors suspected that pulmonary cases could be overlooked because sputum acid-fast bacilli (AFB) microscopy has been a major criterion for defining TB diagnosis.

\section{PATIENTS, MATERIALS AND METHODS}

This is a cross-sectional analysis of stored $\mathrm{ZN}$ stained SSS obtained from patients with TB diagnosed at two public referral laboratories from Juiz de Fora, in 2007. Laboratory 1 is located in a TB regional hospital and performs SSS for hospitalized patients only, while laboratory 2 is a local referral centre and performs SSS in response to outpatient demands. The SSS used in this study are comprised of leftover slides sent by the two laboratories to the State Public Health Reference Laboratory of Minas Gerais, Ezequiel Dias Foundation, for quality control after proper authorization. Confidentiality was assured and the study was approved by the Ethical Research Review Board of the Federal University of Juiz de Fora (protocol 819.125.2006). Sociodemographic data were obtained from notification records at the Department of Epidemiology/Municipal Health Department. No personal information was disclosed and only codes were used for analysis.

Preparation and packing of SSS by laboratories - The preparation of the SSS (smear preparation, fixation and staining of smears) by two involved laboratories was in accordance with the Tuberculosis Guidelines, Ministry of Health (MS 2005). Both laboratories used blank glass slides for preparing the SSS. Following a microscopic exam, these slides were separated with tissue paper and stored at room temperature.

DNA extraction - The available SSS were sent to the Laboratory of Molecular Biology Applied to Mycobacteria at Oswaldo Cruz Foundation (Fiocruz, Rio de Janeiro, Brazil) for DNA extraction, amplification and sequencing of the $\operatorname{oxy} R$ pseudogene.

The oil present on the SSS was removed with xylene. The ZN-stained material was scraped off from the microscopic slides after the addition of $25 \mu \mathrm{L}$ of distilled sterile water. Seventy-five microliters of Chelex suspension was added and after thorough mixing of the samples, the samples were incubated for $30 \mathrm{~min}$ at $97^{\circ} \mathrm{C}$. The samples were centrifuged at $14,000 \mathrm{~g}$ for $10 \mathrm{~min}$. The supernatant was transferred to another tube and stored at $-20^{\circ} \mathrm{C}$ until use in the PCR.

OxyR pseudogene amplification - The primers used were CGCGCTGTCAGAGCTGACTTT and TCTGCGGAATCAGTGTCACC. Forty-five cycles of amplification were performed. The stages were $94^{\circ} \mathrm{C}$ for $10 \mathrm{~s}, 62^{\circ} \mathrm{C}$ for $30 \mathrm{~s}$ and $72^{\circ} \mathrm{C}$ for $15 \mathrm{~s}$ and a final elongation cycle was performed at $72^{\circ} \mathrm{C}$ for $2 \mathrm{~min}$, according to Taylor et al. (1999). A fragment of $150 \mathrm{bp}$ was amplified. The bands generated were analyzed by $2 \%$ agarose gel electrophoresis and visualized by ethidium bromide fluorescence.

$D N A$ sequencing of the oxyR locus - We used sequencing of the $\operatorname{oxy} R$ locus to detect the polymorphism at position 285 of this gene only $M$. bovis has adenine in this position, while the other members of the MTC have guanine. The sequencing reaction is similar to PCR, in which a small sample of DNA is amplified thousands of times in vitro. However, differently from PCR, only one primer is used for synthesis of DNA strands. A mixture containing $1 \mu \mathrm{L}$ of DNA (PCR product), $1 \mu \mathrm{L}$ of primer $3.2 \mathrm{pmol}$ (oxyR Tb1 and oxyR Tb2), $0.5 \mu \mathrm{L}$ of BigDye, $1.5 \mu \mathrm{L}$ of $5 \mathrm{X}$ buffer and $6 \mu \mathrm{L}$ of $\mathrm{H}_{2} \mathrm{O}$ (qsp $10 \mu \mathrm{L}$ ) was prepared. A thermocycler was used to conduct 40 cycles of sequencing. The stages consisted of the following: $96^{\circ} \mathrm{C}$ for $10 \mathrm{~s}$, $50^{\circ} \mathrm{C}$ for $5 \mathrm{~s}$ and $60^{\circ} \mathrm{C}$ for $4 \mathrm{~min}$. The DNA sequencing reaction was performed with BigDye Terminator Cycle 
Sequencing Ready Reaction (Applied Biosystems) and data were generated with an automated instrument $\mathrm{ABI}$ PRISM $^{\circledR} 3730$ Genetic Analyzer, Applied Biosystems. The sequence data were assembled and edited electronically with the SeqScape $2.6 \mathrm{~V}$ program and were compared with a published sequence of the $\operatorname{oxy} \mathrm{R}$ pseudogene of $M$. tuberculosis H37Rv strain (accession U16243).

Epidemiological data collection - Patients' data were obtained from notification records at the Department of Epidemiology/Municipal Health Department of Juiz de Fora. Information such as age, sex, city of residence, AFB results $(0,+,++,+++)$, types of co-morbidities, type of case (if new case, reentry after dropout or recurrence) and information on whether they were institutionalized or referred to Directly Observed Therapy-Short Course (DOTS) were also collected.

The oxyR pseudogene amplification was considered as the main event. Additionally, AFB results were considered the main explanatory variable that could be directly associated with the amount of existing bacilli and, consequently, DNA in the SSS. The interpretation of AFB results by each of the two laboratories that provided the SSS was in accordance with the Tuberculosis Guidelines, Ministry of Health (MS 2005). It is recommended that the reading should cover at least 100 microscopic fields (observation time of approximately $5 \mathrm{~min}$ ) and the results were reported according to the following scale: absence of AFB per field in 100 fields observed (0), presence of less than 1 AFB per field in 100 fields observed (+), presence of 1-10 AFB per field in 50 fields observed $(++)$ and presence of more than 10 AFB per field in 20 fields observed (+++).

Other possible explanatory variables for $\operatorname{oxy} R$ pseudogene amplification were taken into consideration in the analysis, including the laboratory that produced the SSS, age, sex and other medical characteristics (co-morbidities, type of case, DOTS and whether patients were referred from other institutions such as a psychiatric hospital, penitentiary or shelter).

Statistical analysis - An overall description of all available SSS was initially carried out to verify the percentage of $\operatorname{oxy} R$ pseudogene amplification between either AFB results (positive or negative) or laboratories.

For the statistical comparisons, we chose only one of the available SSS for each patient to assure the independence of observations based on the AFB results $(0,+,++$ and +++ ). The AFB results in either duplicate, triplicate or greater were ordered according to numerical codes, and only one of the observations was randomly selected. Only observations with positive AFB smear microscopy or negative AFB smear microscopy with confirmed TB diagnosis by complementary exams were included in the statistical comparisons.

Finally, the percentage of $\operatorname{oxy} R$ pseudogene amplification was estimated among the population, while factors associated with amplification were assessed using logistic regression models for both univariate and multivariate analysis. The difference in proportions was assessed using the Chi-square test and the magnitude of the associations was estimated by the odds ratio (OR) with $95 \%$ confidence interval (CI). The level of significance was 0.05 .
Multivariate analysis attempted to identify the independent association between selected explanatory variables and the presence of $o x y R$ pseudogene amplification. The variables that were associated with $o x y R$ pseudogene amplification in the univariate analysis with significance level $<0.20$ and those with biological or epidemiological relevance were considered for the multivariate logistic regression using manual backward modeling. Only variables with 0.05 significance level remained in the final model. Epi Info was used for data entry (Dean et al. 1994) and R was used for analysis ( $R$ Development Core Team 2005).

\section{RESULTS}

Overall description of all available SSS - An overview of all SSS available (177) will be presented. They were obtained from two public tuberculosis referral laboratories located in Juiz de Fora $(57.1 \%$ and $42.9 \%$ from laboratory 1 and laboratory 2, respectively). Among all SSS available, $156(88.1 \%)$ were positive and $21(11.8 \%)$ were negative for AFB smear microscopy. The oxyR pseudogene was detected in 91 (58.3\%) and nine (42.8\%) in each group, respectively. The proportions of AFBpositive SSS were also similar among laboratories 1 and $2(88.1 \%)$. However, the frequency of oxyR pseudogene detection was higher among SSS from laboratory 1 (76.2\%) compared to laboratory 2 (30.2\%).

Descriptive characteristics of the population - Figure shows a flowchart conducting from the initial 177 specimens to the final selection of 93 slides from 93 valid source patients and the distribution of their frequencies of $\operatorname{oxy} R$ pseudogene amplification stratified by laboratories and positive/negative AFB smear microscopy results. The 177 AFB slide results originated from 99 individuals. The AFB results $(n=6)$ from six individuals were excluded from the statistical analysis because they were negative for AFB smear microscopy without any other confirmatory diagnosis of TB. The remaining 171 AFB results were from 93 patients either with single (54.8\%), duplicate $(21.5 \%)$ or triplicate or greater $(23.8 \%)$ results. Only one of the SSS was randomly selected among AFB results in duplicate, triplicate or more. Among all of the 93 AFB results selected, $83(89.3 \%)$ were positive and $10(10.7 \%)$ were negative for AFB smear microscopy. The oxyR pseudogene was detected in 48 (57.8\%) and six $(60 \%)$ in each group, respectively. The frequency of oxy $R$ pseudogene detection was higher among AFB-positive slides from laboratory $1(84.6 \%)$ compared to laboratory 2 (34\%). Among AFB0 slides, only the laboratory 1 had some amplification of the pseudogene oxyR $(75 \%)$.

Descriptive characteristics of the population $(n=93)$ indicated that $81.7 \%$ were male; the median age was 42 years old (range: 2 months- 85 years old); $2.1 \%$ presented a history of HIV infection, diabetes or mental illness and $26.8 \%$ used alcohol. Additionally, some patients (19.3\%) were referred from other institutions such as a psychiatric hospital, penitentiary or homeless shelter, while more than half of the patients $(53.7 \%)$ were under DOTS. Most patients were new cases (70.9\%), but some (20.4\%) presented a history of recurrence/reentry after dropout. 


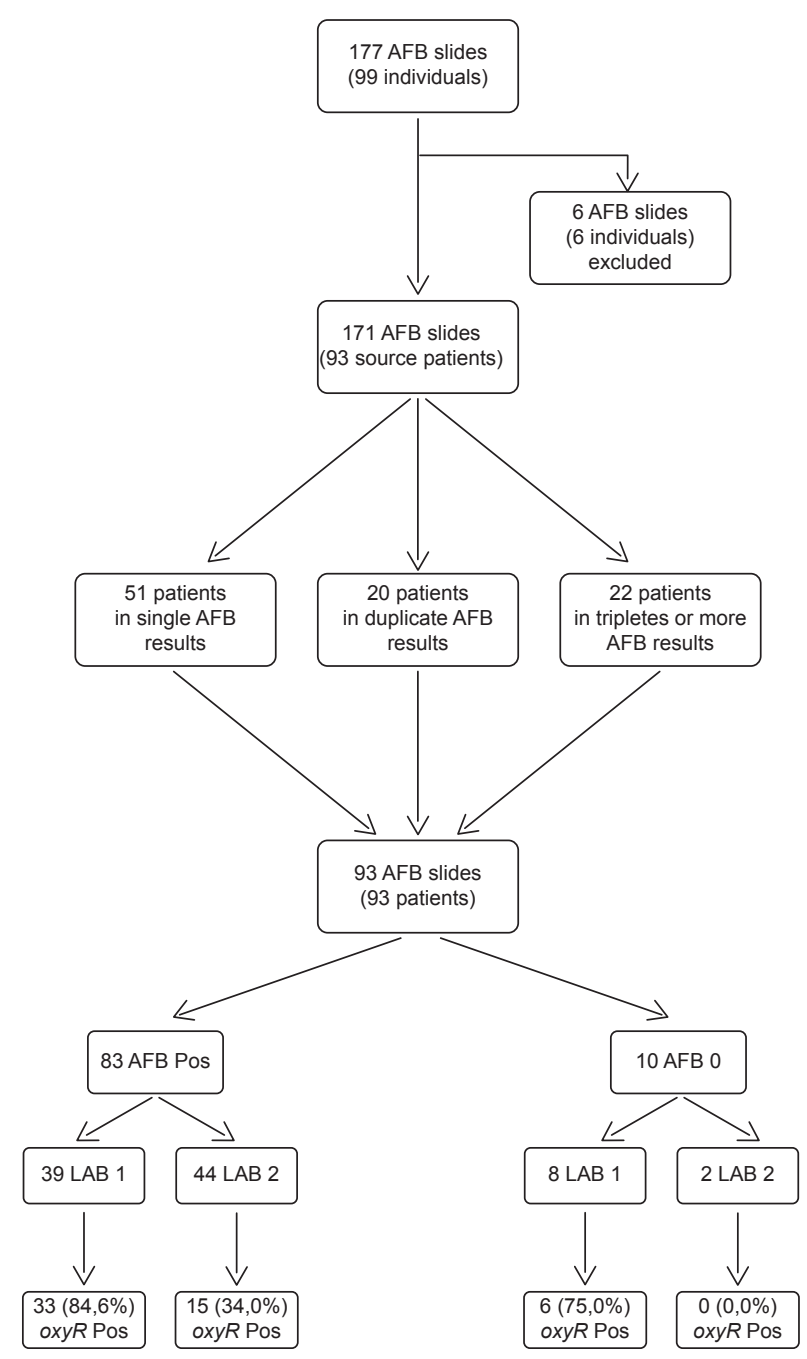

Selection of slides from valid source patients $(\mathrm{n}=93)$ and distribution of their frequencies of oxyR pseudogene amplification by laboratory 1 (LAB 1$)$ /laboratory 2 (LAB 2 ) and positive (Pos)/negative (0) acid-fast bacilli (AFB) results.

The AFB results indicated that $10.8 \%, 45.2 \%, 32.3 \%$ and $11.8 \%$ were $\mathrm{AFB} 0, \mathrm{AFB}+, \mathrm{AFB}++$ and $\mathrm{AFB}+++$, respectively. Approximately half (50.5\%) of the patients were referred from laboratory 1 . Finally, the oxyR pseudogene was detected in $58.1 \%$ patients.

Univariate and multivariate analysis - Univariate analysis $(\mathrm{n}=93)$ indicated that the presence of $\operatorname{oxy} R$ pseudogene amplification was statistically higher for patients who had alcohol use $(\mathrm{OR}=2.92 ; 95 \% \mathrm{CI}=1.02-8.3)$, for those who were referred for DOTS $(\mathrm{OR}=4.37 ; 95 \%$ $\mathrm{CI}=1.70-11.22)$ and for patients who had SSS prepared in laboratory $1(\mathrm{OR}=10.7 ; 95 \% \mathrm{CI}=3.78-26.82)($ Table I). Finally, multivariate analysis indicated two variables that were statistically associated with presence of the $\operatorname{oxy} R$ amplification: $\mathrm{AFB}++$ results by smear microscopy (OR $=8.06 ; 95 \% \mathrm{IC}=1.11-58.52)$ and SSS prepared in laboratory $1(\mathrm{OR}=21.40 ; 95 \% \mathrm{IC}=5.95-76.90)($ Table II).

\section{DISCUSSION}

We have demonstrated the capability of amplifying and sequencing the oxyR pseudogene from stored SSS. However, we could not identify any molecular profile consistent with M. bovis.

The observed relationship between alcohol use and DOTS with $\operatorname{oxy} R$ pseudogene amplification was only verified in the univariate analysis and can potentially be attributed to a confounding effect of the source laboratory. Patients who reported alcohol use and those who were referred for DOTS were preferentially diagnosed in laboratory 1 ( $\mathrm{p}$ value $<0.05$ ). As shown, the association between these explanatory variables and the outcome of interest did not remain significant when adjusting for laboratory in the stratified and multivariate analyses.

The expected trend of the higher chance of $\operatorname{oxy} R$ pseudogene amplification in AFB-positive patients was not evidenced in the univariate analysis, perhaps due to a lack of statistical power. However, the independent association between $\mathrm{AFB}++$ and the oxyR pseudogene amplification was evidenced in the multivariate analysis, a model that also took into account the laboratory that processed the SSS. Zink and Nerlich (2004) were able to distinguish the molecular profile of $M$. bovis from the rest of the MTC using formalin-fixed and paraffin wax-embedded biopsy tissue samples and concluded that different amounts and varying preservation states of the DNA samples could more easily affect the amplification of single copy genes, such as oxyR, compared to multi copy genes. The lack of association between AFB+++ and amplification of the pseudogene $o x y R$ in the multivariate analysis was most likely due to the small sample size.

The greater chance of the $\operatorname{xy} R$ pseudogene amplification found in patients who had SSS prepared in laboratory 1 compared to laboratory 2 deserves attention. A potential explanation for such a difference may lie in the packing, transportation and/or processing of specimens, which may have affected the DNA integrity of the specimens. In laboratory 1 , the preparation of the SSS was done no later than $24 \mathrm{~h}$ after sputum collection. However, in laboratory 2, the sputum samples were sent from the primary health unit to a central unit where they were kept for a week before being forwarded to the laboratory where the SSS were prepared for microscopy. This excessive delay between sputum collection and smear preparation is of public health importance and quality assurance should be a concern in such settings.

Zink and Nerlich (2004) argued that the chemical processing of stored materials is another factor that induces changes in DNA, potentially resulting in its partial or complete degradation. However, as the SSS of the two laboratories were apparently prepared using the same process of standardized staining $(\mathrm{ZN})$, chemical processing should not be a factor influencing the different levels of $\operatorname{oxy} R$ pseudogene amplification.

It is feasible that the positive AFB smears that did not have the amplified oxyR pseudogene may be a result of atypical mycobacteria, which also could be differentially distributed between the two laboratories. However, another study conducted by the same team in Juiz de Fora, involving 156 patients with TB diagnosed from March 2008-February 2010 in the same laboratories, revealed that the levels of atypical mycobacteria were 
TABLE I

Univariate analysis of the $\operatorname{oxy} R$ pseudogene amplification, Juiz de Fora, Minas Gerais, $2007(\mathrm{n}=93)$

\begin{tabular}{|c|c|c|c|c|}
\hline \multirow[b]{2}{*}{ Variables } & \multicolumn{3}{|c|}{ oxyR pseudogene amplification } & \multirow[b]{2}{*}{$\mathrm{p}$ value } \\
\hline & Total & $\operatorname{Pos}^{a}(\%)$ & OR (CI 95\%) & \\
\hline \multicolumn{5}{|l|}{ Sex } \\
\hline Female & 17 & $7(41.2)$ & 1.00 & - \\
\hline Male & 76 & $47(61.8)$ & $2.31(0.79-6.75)$ & 0.12 \\
\hline \multicolumn{5}{|l|}{ Age } \\
\hline$>42$ & 42 & $23(54.8)$ & 1.00 & - \\
\hline$\leq 42$ & 42 & $26(61.9)$ & $1.34(0.51-3.52)$ & 0.50 \\
\hline \multicolumn{5}{|l|}{ History of HIV infection ${ }^{b}$} \\
\hline No & 74 & $42(56.8)$ & $0(0.0-5.73)$ & 0.22 \\
\hline Yes & 2 & $2(100)$ & 1.00 & - \\
\hline \multicolumn{5}{|l|}{ Alcohol use $(\text { ever })^{b}$} \\
\hline No & 47 & $22(46.8)$ & 1.00 & - \\
\hline Yes & 25 & $18(72)$ & $2.92(1.02-8.3)$ & $<0.05$ \\
\hline \multicolumn{5}{|l|}{ Referred from other institution ${ }^{b}$} \\
\hline No & 63 & $33(52.4)$ & 1.00 & - \\
\hline Yes & 18 & $14(77.8)$ & $3.18(0.94-10.73)$ & 0.06 \\
\hline \multicolumn{5}{|l|}{ DOTS $^{b}$} \\
\hline No & 33 & $13(39.4)$ & 1.00 & - \\
\hline Yes & 50 & $37(74)$ & $4.37(1.70-11.22)$ & $<0.01$ \\
\hline \multicolumn{5}{|l|}{ Type of case ${ }^{b}$} \\
\hline Recurrence/reentry after dropout & 19 & $9(47.4)$ & 1.00 & - \\
\hline New case & 66 & $41(62.1)$ & $1.82(0.65-5.09)$ & 0.25 \\
\hline \multicolumn{5}{|l|}{ AFB results } \\
\hline AFB0 & 10 & $6(60)$ & 1.00 & - \\
\hline $\mathrm{AFB}+$ & 42 & $23(54.8)$ & $0.80(0.19-3.28)$ & 0.76 \\
\hline $\mathrm{AFB}++$ & 30 & $19(63.3)$ & $1.15(0.26-4.99)$ & 0.85 \\
\hline $\mathrm{AFB}+++$ & 11 & $6(54.5)$ & $0.80(0.14-4.53)$ & 0.80 \\
\hline \multicolumn{5}{|l|}{ Laboratories } \\
\hline 1 & 47 & $39(83)$ & $10.07(3.78-26.82)$ & $<0.001$ \\
\hline 2 & 46 & $15(32.6)$ & 1.00 & - \\
\hline
\end{tabular}

a: oxyR pseudogene amplified (Mycobacterium tuberculosis complex); b: excluding missing values; AFB: acid-fast bacilli; CI: confidence interval; DOTS: Directly Observed Therapy-Short Course; HIV: human immunodeficiency virus; OR: odds ratio; Pos: positive.

low and evenly distributed between laboratories. The classical biochemical methods showed 151 (96.79\%) M. tuberculosis, three (1.92\%) M. avium intracellulare, one $(0.64 \%)$ M. tuberculosis-M. avium intracellulare co-infection and one $(0.64 \%)$ M. tuberculosis-M. bovis co-infection (unpublished observations). This percentage of atypical mycobacteria (6\%) was slightly lower than that found by Froes et al. (2003).

Also of public health and medical interest is the amplification of the $\operatorname{oxy} R$ pseudogene in a considerable por- tion (75\%) of patients from laboratory 1 who had both negative results for AFB smear microscopy and a positive culture for mycobacteria. These results suggest a potential ability of the oxyR pseudogene amplification in detecting the $M T C$ even in SSS from paucibacillary patients. This identification of mycobacteria by molecular methods in paucibacillary sputum from either fresh or stored specimens could be an important strategy to be used among patients who cannot wait for the results of traditional diagnosis such as a mycobacteria culture. 


\section{TABLE II}

Multivariate logistic regression model for the amplification of the $\operatorname{oxy} R$ pseudogene, Juiz de Fora, Minas Gerais, $2007(\mathrm{n}=93)$

\begin{tabular}{|c|c|c|}
\hline \multirow{2}{*}{ Variables } & \multicolumn{2}{|c|}{$\begin{array}{l}\text { oxy } R \text { pseudogene } \\
\text { amplification }\end{array}$} \\
\hline & OR (IC 95\%) & $\mathrm{p}$ value \\
\hline \multicolumn{3}{|c|}{ AFB smear microscopy results } \\
\hline AFB0 & 1.0 & - \\
\hline $\mathrm{AFB}+$ & $1.61(0.29-8.80)$ & 0.57 \\
\hline $\mathrm{AFB}++$ & $8.06(1.11-58.52)$ & 0.03 \\
\hline $\mathrm{AFB}+++$ & $2.93(0.31-27.38)$ & 0.34 \\
\hline \multicolumn{3}{|c|}{$\begin{array}{l}\text { Laboratories that processed } \\
\text { the sputum smears }\end{array}$} \\
\hline 1 & $21.40(5.95-76.90)$ & - \\
\hline 2 & 1.0 & $<0,001$ \\
\hline
\end{tabular}

AFB: acid-fast bacilli; OR: odds ratio.

Some limitations of this study should be discussed. This is an exploratory study in which the samples were not randomly drawn but were remnants of SSS sent to the Public Health Center Laboratory for quality control. Most of the slides were AFB-positive because in the absence of culture, the result of AFB was a major criterion for defining diagnosis of TB. It should be noted that only pulmonary cases were included in which $M$. bovis is less frequent. The study also only involved laboratories located in urban areas, which may reduce the inclusion of patients from rural areas where M. bovis may have a higher prevalence. In addition, the small sample size from only one municipality and lack of representativeness may jeopardise generalization of our results.

Although M. bovis was not found in the examined samples, the high percentage of pseudogene $o x y R$ amplification (MTC) in our samples may indicate that the analysis of nucleotide polymorphisms at position 285 of $\operatorname{xy} R$ in stored SSS can be used to obtain estimates of the prevalence or incidence rates of human infections caused by $M$. bovis. In addition to Brazil, this strategy could be expanded for epidemiological purposes in areas such as Africa, Southeast Asia, Central America, South America and other regions where transmission of $M$. bovis from animals to humans and vice-versa can occur or is a suspected problem.

With patients who fail in the first regimen for tuberculosis treatment or develop AFB-negative paucibacillary tuberculosis, it may be difficult to obtain new positive cultures due to the effect of therapy on mycobacteria and difficulties in collecting new samples, even by bronchial lavage. In these situations, the stored SSS can also be an alternative for the identification of involved mycobacterium species by molecular methods; this will be a particularly useful strategy for most developing countries where the isolation and characterization of mycobacteria are not routinely practiced at the start of tuberculosis treatment.
Sreevatsan et al. (1996) analyzed the polymorphism at nucleotide 285 in the $\operatorname{oxy} R$ pseudogenes of MTC organisms from widespread geographic sources and host species and indicated that it was $100 \%$ sensitive and specific for distinguishing $M$. bovis isolates from other members of the MTC. Either direct sequencing of amplified DNA or PCR-restriction fragment length polymorphism strategies were used to identify the polymorphism at nucleotide 285 in the $\operatorname{oxy} R$ pseudogene. While those strategies have been extensively applied to DNA extracted from MTC isolates (Sreevatsan et al. 1996, Espinosa de los Monteros et al. 1998), they are rarely used in primary clinical specimens and archived fixed tissues (Zink \& Nerlich 2004).

Finally, despite the limitations of this study and the need for further work to assess the validity and reliability of these findings, the amplification and sequencing of the $\operatorname{oxy} R$ pseudogene from stored ZN-stained SSS has a potential public health application as a complementary method of diagnosis for tuberculosis, especially in areas or populations where $M$. bovis is more prevalent.

\section{REFERENCES}

Blázquez J, Espinosa de Los Monteros LE, Samper S, Martín C, Guerrero A, Cobo J, Van Embden J, Baquero F, Gómez-Mampaso E 1997. Genetic characterization of multidrug-resistant Mycobacterium bovis strains from a hospital outbreak involving human immunodeficiency virus-positive patients. J Clin Microbiol 35: 1390-1393.

Collins CH, Grange JM 1983. The bovine tubercle bacillus. J Appl Bacteriol 55: 13-29.

Cosivi O, Grange JM, Daborn CJ, Raviglione MC, Fujikura T, Cousins D, Robinson RA, Huchzermeyer HF, de Kantor I, Meslin FX 1998. Zoonotic tuberculosis due to Mycobacterium bovis in developing countries. Emerg Infect Dis 4: 59-70.

Cosivi O, Meslin FX, Daborn CJ, Grange JM 1995. Epidemiology of Mycobacterium bovis infection in animals and humans, with particular reference to Africa. Rev Sci Tech 14: 733-746.

Da Silva Rocha A 2009. Doenças micobacterianas de relevância máxima: I - Tuberculose humana e Mycobacterium bovis. II Hanseníase, recidiva, re-infecção e resistência bacteriana a drogas dos esquemas terapêuticos propostos pela Organização Mundial da Saúde, PhD Thesis, Universidade Federal do Rio de Janeiro, Rio de Janeiro, 308 pp.

Daborn CJ, Grange JM 1993. HIV/AIDS and its implications for the control of animal tuberculosis. Br Vet J 149: 405-417.

Dankner WM, Davis CE 2000. Mycobacterium bovis as a significant cause of tuberculosis in children residing along the United StatesMexico border in the Baja California region. Pediatrics 105: E79.

Dankner WM, Waecker NJ, Essey MA, Moser K, Thompson M, Davis CE 1993. Mycobacterium bovis infections in San Diego: a clinicoepidemiologic study of 73 patients and a historical review of a forgotten pathogen. Medicine (Baltimore) 72: 11-37.

Dean AG, Dean JA, Coulombier D, Brendel KA, Smith DC, Burton AH, Dicker RC, Sullivan K, Fagan RF, Arner TG 1994. Epi Info Version 6, Centers for Diseases Control and Prevention, Atlanta, GA.

Espinosa de los Monteros LE, Galán JC, Gutiérrez M, Samper S, García Marín JF, Martín C, Domínguez L, de Rafael L, Baquero F, Gómez-Mampaso E, Blázquez J 1998. Allele-specific PCR method based on pncA and $\operatorname{xy} R$ sequences for distinguishing Mycobacterium bovis from Mycobacterium tuberculosis: intraspecific $M$. bovis pncA sequence polymorphism. J Clin Microbiol 36: 239-242. 
Evans JT, Smith EG, Banerjee A, Smith RM, Dale J, Innes JA, Hunt D, Tweddell A, Wood A, Anderson C, Hewinson RG, Smith NH, Hawkey PM, Sonnenberg P 2007. Cluster of human tuberculosis caused by Mycobacterium bovis: evidence for person-to-person transmission in the UK. Lancet 369: 1270-1276.

Farr SB, Kogoma T 1991. Oxidative stress responses in Escherichia coli and Salmonella typhimurium. Microbiol Rev 55: 561-585.

Froes GC, Coutinho RL, Nardy de Ávila M, Cançado LR, Spíndola de Miranda S 2003. Perfil e seguimento dos pacientes portadores de Mycobacterium sp. do Hospital das Clínicas da Universidade Federal de Minas Gerais. J Bras Pneumol 29: 365-370.

Konno K, Feldmann FM, McDermott W 1967. Pyrazinamide susceptibility and amidase activity of tubercle bacilli. Am Rev Respir Dis 95: 461-469.

LoBue PA, Betacourt W, Peter C, Moser KS 2003. Epidemiology of Mycobacterium bovis disease in San Diego County, 1994-2000. Int J Tuberc Lung Dis 7: 180-185.

Long R, Nobert E, Chomyc S, van Embden J, McNamee C, Duran RR, Talbot J, Fanning A 1999. Transcontinental spread of multidrug-resistant Mycobacterium bovis. Am J Respir Crit Care Med 159: 2014-2017.

MAPA - Ministério da Agricultura, Pecuária e Abastecimento, Brasil 2006. Programa Nacional de Controle e Erradicação da Brucelose e da Tuberculose Animal (PNCEBT), MAPA/SDA/ DSA, Brasília, 188 pp.

MS - Ministério da Saúde, Brasil 2005. Manual de bacteriologia da tuberculose, 3rd ed., Centro de Referência Professor Hélio Fraga, Secretaria de Vigilância em Saúde, Rio de Janeiro, 240 pp.

PAHO - Pan American Health Organization 1991. Health conditions in the Americas, 1990, vol. I, scientific publication 524, Pan American Health Organization, Washington DC, 404 pp.

$\mathrm{R}$ Development Core Team 2005. R: a language and environment for statistical computing. R Foundation for Statistical Computing, Vienna, Austria. Available from: http://www.R-project.org. [accessed 2005].
Rivero A, Márquez M, Santos J, Pinedo A, Sánchez MA, Esteve A, Samper S, Martín C 2001. High rate of tuberculosis reinfection during a nosocomial outbreak of multidrug-resistant tuberculosis caused by Mycobacterium bovis strain B. Clin Infect Dis 32: 159-161.

Roxo E 1997. Mycobacterium bovis como causa de zoonose. Rev Cienc Farm 18: 101-108.

Samper S, Martín C, Pinedo A, Rivero A, Blázquez J, Baquero F, van Soolingen D, van Embden J 1997. Transmission between HIVinfected patients of multidrug-resistant tuberculosis caused by Mycobacterium bovis. AIDS 11: 1237-1242.

Sherman DR, Sabo PJ, Hickey MJ, Arain TM, Mahairas GG, Yuan Y, Barry CE 3rd, Stover CK 1995. Disparate responses to oxidative stress in saprophytic and pathogenic mycobacteria. Proc Natl Acad Sci USA 92: 6625-6629.

Sreevatsan S, Escalante P, Pan X, Gillies DA 2nd, Siddiqui S, Khalaf CN, Kreiswirth BN, Bifani P, Adams LG, Ficht T, Perumaalla VS, Cave MD, van Embden JD, Musser JM 1996. Identification of a polymorphic nucleotide in $\operatorname{oxy} R$ specific for Mycobacterium bovis. J Clin Microbiol 34: 2007-2010.

Sreevatsan S, Pan X, Zhang Y, Deretic V, Musser JM 1997. Analysis of the $\operatorname{oxyR}$-ahpC region in isoniazid-resistant and susceptible Mycobacterium tuberculosis complex organisms recovered from diseased humans and animals in diverse localities. Antimicrob Agents Chemother 41: 600-606.

Taylor GM, Goyal M, Legge AJ, Shaw RJ, Young D 1999. Genotypic analysis of Mycobacterium tuberculosis from medieval human remains. Microbiology 145: 899-904.

Wedlock DN, Skinner MA, de Lisle GW, Buddle BM 2002. Control of Mycobacterium bovis infections and the risk to human populations. Microbes Infect 4: 471-480.

Wilkins EG, Griffiths RJ, Roberts C 1986. Bovine variants of Mycobacterium tuberculosis isolated in Liverpool during the period 1969 to 1983: an epidemiological survey. Q J Med 59: 627-635.

Zink AR, Nerlich AG 2004. Molecular strain identification of the Mycobacterium tuberculosis complex in archival tissue samples. J Clin Pathol 57: 1185-1192. 